\title{
Inhibition of Heparanase Expression Results in Suppression of Invasion, Migration and Adhesion Abilities of Bladder Cancer Cells
}

\author{
Yoshihiro Tatsumi ${ }^{1,2}$, Makito Miyake ${ }^{1}{ }^{\mathbb{D}}$, Keiji Shimada ${ }^{2}$, Tomomi Fujii ${ }^{2} \mathbb{D}$, Shunta Hori ${ }^{1}$, \\ Yosuke Morizawa ${ }^{1}{ }^{\mathbb{D}}$, Yasushi Nakai ${ }^{1}$, Satoshi Anai ${ }^{1}$, Nobumichi Tanaka ${ }^{1}$, Noboru Konishi ${ }^{2}$ \\ and Kiyohide Fujimoto $1, * \mathbb{C}$ \\ 1 Department of Urology, Nara Medical University, 840 Shijo-cho, Nara 634-8522, Japan; \\ takuro.birds.nest@gmail.com (Y.T.); makitomiyake@yahoo.co.jp (M.M.); horimaus@gmail.com (S.H.); \\ tigers.yosuke@gmail.com (Y.M.); nakaiyasusiuro@live.jp (Y.N.); sanai@naramed-u.ac.jp (S.A.); \\ sendo@naramed-u.ac.jp (N.T.) \\ 2 Department of Pathology, Nara Medical University, 840 Shijo-cho, Nara 634-8522, Japan; \\ k-shimada@nara-jadecom.jp (K.S.); fujiit@naramed-u.ac.jp (T.F.); n-konishi@takai-hp.com (N.K.) \\ * Correspondence: kiyokun@naramed-u.ac.jp; Tel.: +81-744-22-3051 (ext. 2338)
}

Received: 28 April 2020; Accepted: 26 May 2020; Published: 27 May 2020

\begin{abstract}
Heparan sulfate proteoglycan syndecan-1, CD138, is known to be associated with cell proliferation, adhesion, and migration in malignancies. We previously reported that syndecan-1 (CD138) may contribute to urothelial carcinoma cell survival and progression. We investigated the role of heparanase, an enzyme activated by syndecan-1 in human urothelial carcinoma. Using human urothelial cancer cell lines, MGH-U3 and T24, heparanase expression was reduced with siRNA and RK-682, a heparanase inhibitor, to examine changes in cell proliferation activity, induction of apoptosis, invasion ability of cells, and its relationship to autophagy. A bladder cancer development mouse model was treated with RK-682 and the bladder tissues were examined using immunohistochemical analysis for Ki-67, E-cadherin, LC3, and CD31 expressions. Heparanase inhibition suppressed cellular growth by approximately $40 \%$ and induced apoptosis. The heparanase inhibitor decreased cell activity in a concentration-dependent manner and suppressed invasion ability by $40 \%$. Inhibition of heparanase was found to suppress autophagy. In N-butyl-N-(4-hydroxybutyl) nitrosamine (BBN)-induced bladder cancer mice, treatment with heparanase inhibitor suppressed the progression of cancer by $40 \%$, compared to controls. Immunohistochemistry analysis showed that heparanase inhibitor suppressed cell growth, and autophagy. In conclusion, heparanase suppresses apoptosis and promotes invasion and autophagy in urothelial cancer.
\end{abstract}

Keywords: heparanase; syndecan-1; heparan sulfate proteoglycans (HSPGs); urothelial carcinoma

\section{Introduction}

Heparan sulfate proteoglycans (HSPGs) are glycoproteins containing heparan sulfate (HS) groups that are covalently attached [1]. They are widely expressed and play critical roles in numerous cellular processes, including endocytosis, migration, and adhesion. Their actions are mediated through interactions with ligands such as growth factors, cytokines, extracellular matrix proteins, and enzymes. HSPGs are also involved in the malignant transformation of cells. Growth factors are released through cellular degradation, which promote the invasion and proliferation of cancer cells [2,3]. Syndecan-1 (SDC1) is an HSPG that is overexpressed in both normal and malignant cells, contributing to the development of hematopoietic and carcinoma development [4-9]. Syndecan-1 regulates substance permeation and constitutes a reservoir for various growth factors and cytokines in the basement 
membrane of cells. It plays a critical role in the progression and invasion of urothelial cancer through enhanced angiogenesis.

We have previously reported that syndecan-1 (CD138) suppresses apoptosis and increases the capacity for cell proliferation via junB-FLIP long signal in urothelial cancer [10]. Urothelial cancers can be broadly classified into low-grade, non-invasive, and high-grade invasive cancers [11]. Invasive urothelial cancers exhibit significantly higher syndecan-1 expression. In vitro experiments showed that knocking down syndecan-1 using siRNA induces cellular apoptosis and decreases the capacity for cellular proliferation. The enzyme heparanase controls the activation of syndecan-1.

Heparanase is an endoglycosidase enzyme that targets HSPG proteins expressed in the extracellular matrix (ECM) and basement membrane (BM) for degradation [12]. Heparanase activation expedites the movement of tumor cells through the ECM and BM, facilitating metastasis. Heparanase is also known to be expressed in many types of malignant tumors, and is associated with metastasis and angiogenesis $[13,14]$. Heparinase cleavage of HSPGs produces soluble proteins that infiltrate into the tumor microenvironment, where they interact with ligands such as growth factors, modifying signaling pathways [15]. SDC1 in the stroma promotes breast carcinoma growth by enhancing FGF2 signaling [16]. Heparanase-neutralizing antibodies have been suggested for the treatment of diffuse non-Hodgkin's B-cell and follicular lymphomas [17] through the inhibition of cell invasion and tumor metastasis processes [17-19]. Recently, a small molecule inhibitor of heparanase was shown to reduce metastatic characteristics in a hepatocellular carcinoma model [20]. In vivo studies using heparanase inhibitors in animal tumor models have also demonstrated reductions in tumor metastasis [21-23]. As heparinase is absent or expressed at low levels in normal tissue [24,25], it may be a potential target candidate for therapeutic interventions. Various studies have investigated the underlying mechanism for heparanase activity in cancer, including enhancement of angiogenesis and promotion of apoptosis and autophagy $[14,26-30]$. Reports indicate that autophagy contributes to chemotherapy resistance development, making this an important research focus area.

In this study, we analyzed the function of heparanase, an activator of syndecan-1, in angiogenesis, apoptosis, and autophagy. The aim was to establish heparanase as a target for molecular therapy in urothelial carcinoma.

\section{Results}

\subsection{Heparanase Is Overexpressed in Human Urothelial Carcinoma of the Urinary Bladder, and Heparanase Expression Levels Are Associated with Intravesical Recurrence}

The patterns of heparanase expression in resected bladder cancer tissue samples were analyzed using immunohistochemical (IHC) staining. The relationship between heparanase expression and recurrence, metastasis, and prognosis of urothelial cancer was examined. Tissue specimens $(n=57)$ were resected from the renal pelvis, ureter, and bladder of patients with multifocal onset, relapse, metastasis, and prognosis cases of urothelial cancer. Table 1 summarizes patient clinicopathological data using the 2009 World Health Organization (WHO) grading and staging of tumors classification [31]. The total number of Ta cases was 20 and the grade was low grade:high grade, 13:7. Among the 17 cases of T1, low grade:high grade, 3:14, and all 10 cases of Tis were high grade.

Table 1. Characterization of urothelial carcinomas.

\begin{tabular}{cccc}
\hline & $p$ Ta $(n=\mathbf{2 0})$ & $p$ T1 $(n=\mathbf{1 7})$ & $p$ Tis $(n=10)$ \\
\hline Age & $71.3(61-82)$ & $72.9(5-80)$ & $72.4(62-86)$ \\
Gender (M:F) & $16: 4$ & $14: 3$ & $8: 2$ \\
Grade & & & \\
Low grade & 13 & 3 & 0 \\
High grade & 7 & 14 & 10 \\
\hline
\end{tabular}

$p \mathrm{Ta}=$ low-grade non-muscle invasive bladder cancer; $p \mathrm{~T} 1$ = intermediate risk non-muscle invasive bladder cancer; $p$ Tis $=$ in situ neoplasia. 
The expression of heparanase is diffusely expressed in both the cell membrane and cytoplasm. The expression of heparanase protein was approximately $10 \%$ in normal urothelium but increased to approximately $30 \%$ in urothelial carcinoma samples $(p<0.05)$. Heparanase expression was elevated in high-grade compared to low-grade carcinoma samples ( $34.7 \%$ vs. $23.4 \%$, respectively) (Figure 1a,b). The immunohistochemical staining of surgically resected specimens from 47 bladder cancer patients showed that positive heparanase expression was observed predominantly in cases exhibiting intravesical relapse $(p<0.05)$ (Figure 1c).

(a)

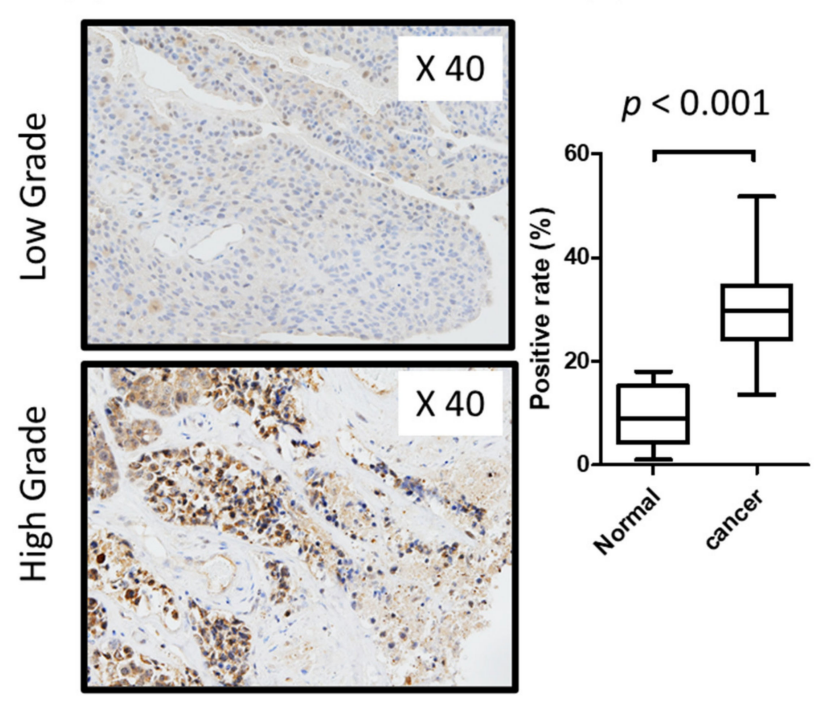

(b)

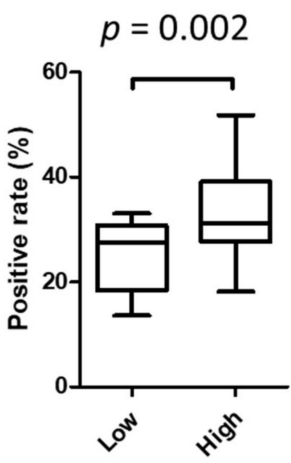

(c)
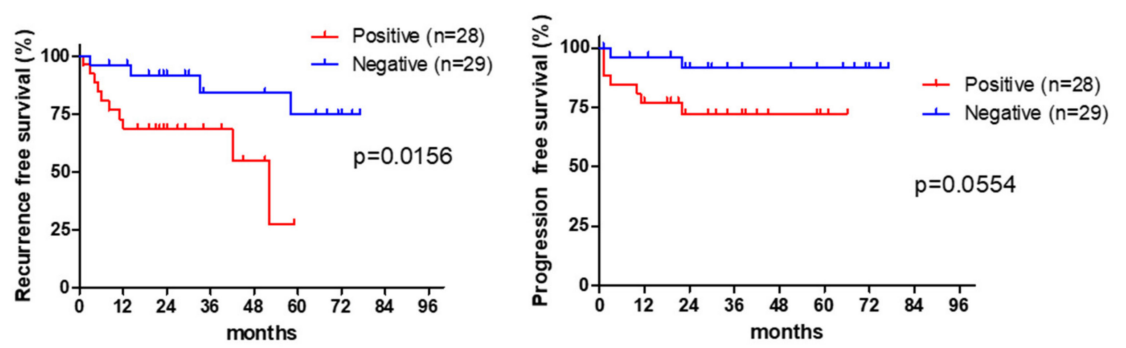

Figure 1. Immunohistological examination of expression of heparanase in bladder tissue; (a) positive ratio in low grade bladder cancer and high grade bladder cancer; (b) heparanase expression rate; (c) Kaplan-Meier curve of intravesical recurrence and invasion.

\subsection{Knockdown of Heparanase-Induced Apoptosis in Urothelial Carcinoma Cells}

Heparanase expression was studied in the human urothelial cancer cell lines MGH-U3 and T24 and found to increase compared to the normal urothelial cell line (UROtsa). The expression levels of heparanase were similar in MGH-U3 and T24 (Supplementary Figure S1). We first examined the suppression of heparanase protein expression and mRNA expression by knockdown with Si RNA (Supplementary Figure S2). MGH-U3 showed a significant decrease in cell activity due to heparanase knockdown compared to T24. There is a difference that MGH-U3 cells are suppressed by about $15 \%$ and T24 cells are suppressed by about $25 \%$ by knockdown by Si RNA. Inhibiting the expression of heparanase by siRNA suppressed the proliferative activity of cancer cells strongly, and cytotoxicity was observed (Figure 2a). In the MGH-U3 cell line, proliferation activity was suppressed by approximately $80 \%$ compared to approximately $40 \%$ in T24 cells. In the UROtsa cell line, heparanase knockdown suppressed growth activity by $15 \%$. Further, heparanase knock-down by siRNA induced apoptosis (Figure 2b). 
(a) UROtsa
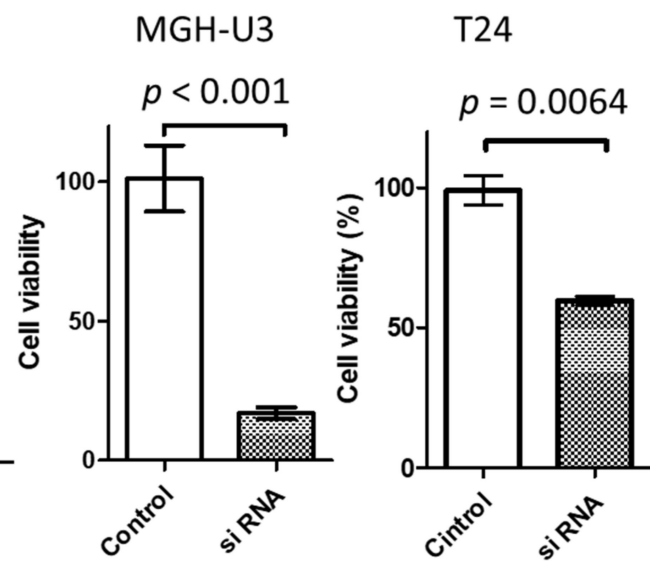

$(n=3)$

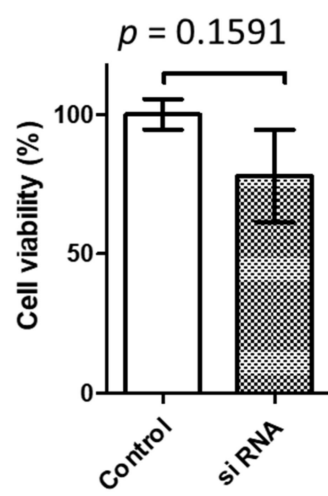

(2 times)

(b)

\section{Control}
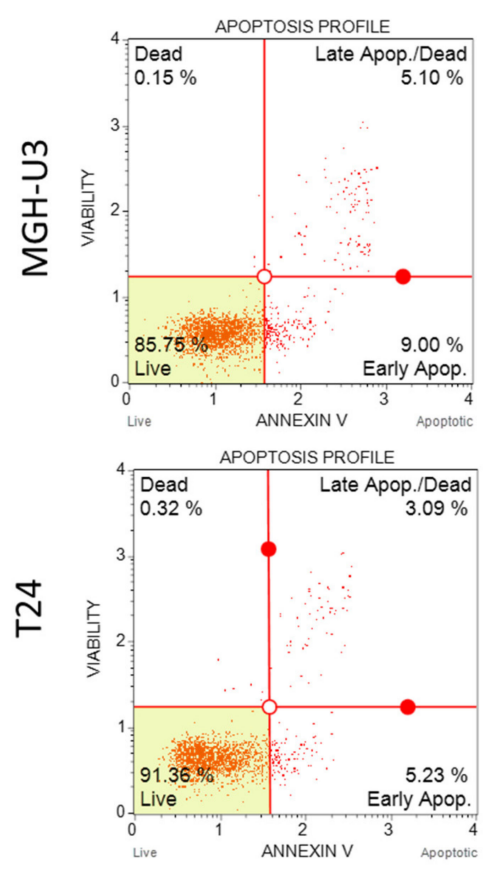

si RNA
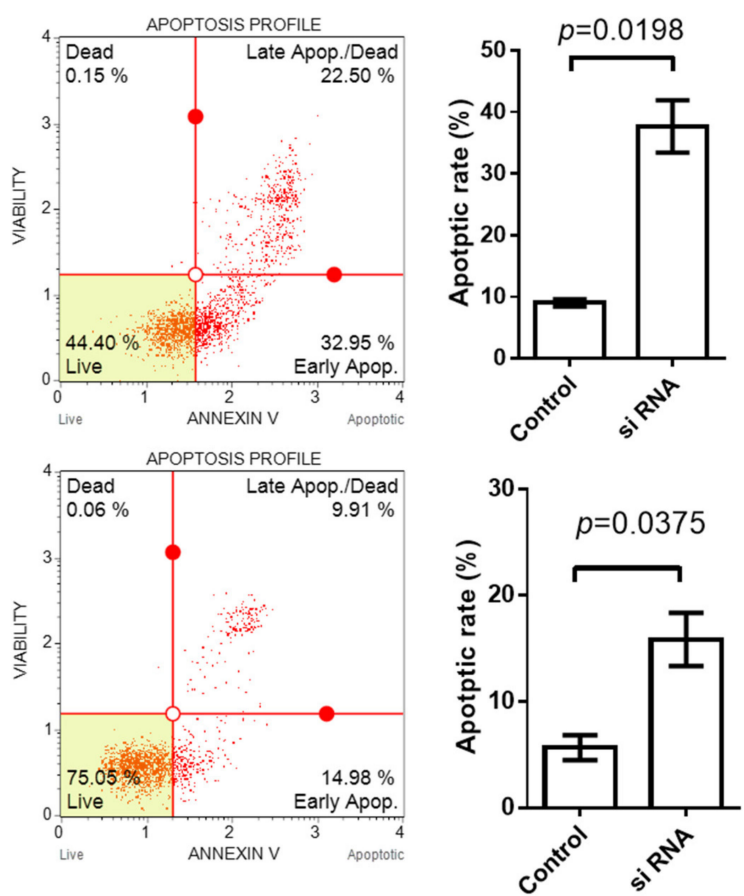

Figure 2. (a) Effect of heparanase knockdown on cell survival in urothelial carcinoma cells. Cell viability was assessed by an MTS assay $72 \mathrm{~h}$ following transfection; (b) $48 \mathrm{~h}$ following transfection, cells stained with Annexin $\mathrm{V}$ and propidium iodide were analyzed by flow cytometry (upper panels) and the percentages of apoptotic cells (AV[+]/PI[])] calculated (lower panels). Inset photograph is an immunofluorescence microscopy image showing cells positive for FITC-conjugated Annexin V (AV). Each value is the mean \pm standard error. C, control RNA (non-specific siRNA); Si RNA, heparanase siRNA.

2.3. The Multi Enzyme Inhibitor RK-682, Which Is Also a Heparanase Inhibitor, Suppresses Cell Proliferation and Autophagy in Human Urothelial Cancer Cell Lines

RK-682 is an inhibitor of various enzymes including heparanase, phospholipase A_2, HIV-1 protease, some dual-specificity phosphatases (DSP), and a protein tyrosine phosphatase (PTP), CD45. The inhibition of heparanase by RK-682 was examined using MGH-U3 and T24 cell lines. Treatment with RK-682 suppressed heparanase protein expression and mRNA expression in these cells (Supplementary Figure S3). MGH-U3 and T24 cell lines were treated with RK-682 and examined in a cell viability assay to determine cytotoxicity. RK-682-treated MGH-U3 and T24 cells showed a concentration-dependent cytotoxicity (Figure 3a). The half-maximal inhibitory concentration (IC50) of RK-682 was $78.2 \mathrm{nM}$ in 
MGH-U3 cells, $43.2 \mathrm{nM}$ in T24 cells, and $145 \mathrm{nM}$ in UROtsa. The cytotoxicity was 2-3 times higher than that of the cancer cell line. UROtsa, which has low expression of heparanae, has an IC50 of RK-682 about 2-3 times higher than that of urothelial carcinoma cell line, MGH-U3 cell line and T24 cell line which has high expression of heparanase. In the heparanse knockdown experiment with $\mathrm{Si}$ RNA, the UROtsa cell line showed almost no inhibition of the cell activity, whereas RK-682 inhibited the cell activity of the UROtsa cell line at a high concentration. From this fact, it is considered that RK-682 has an action other than the inhibition of heparanase. The effect of RK-682 treatment was also examined in an invasion migration assay. In MGH-U3 and T24 cell lines, migratory ability decreased by approximately $20 \%$ following treatment with RK-682. In RK-682-treated MGH-U3 and T24 cells, invasion ability reduced by 55\% and 40\%, respectively (Figure 3b). MGH-U3 and T24 cells treated with RK-682 were also tested in an autophagy assay. The expression of autophagy decreased following the treatment with RK-682 (Figure 3c).
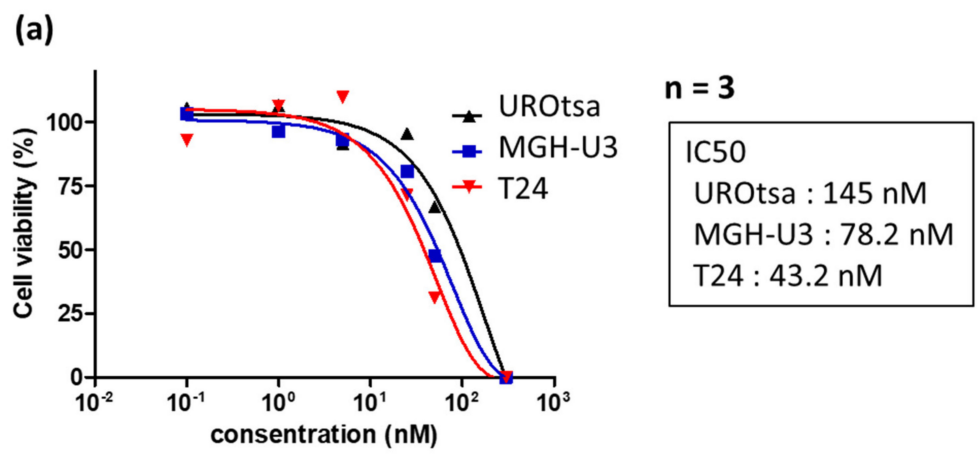

(b)
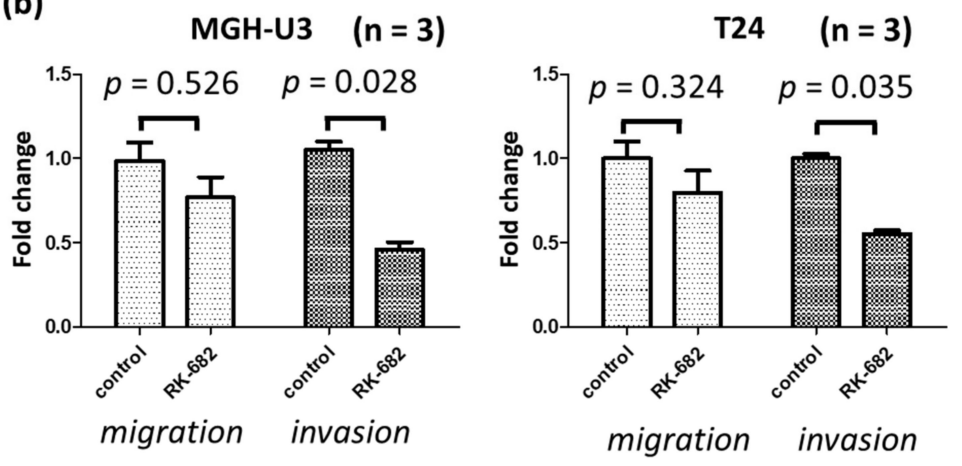

(c)

MGH-U3 $(n=3)$

T24 (n=3)
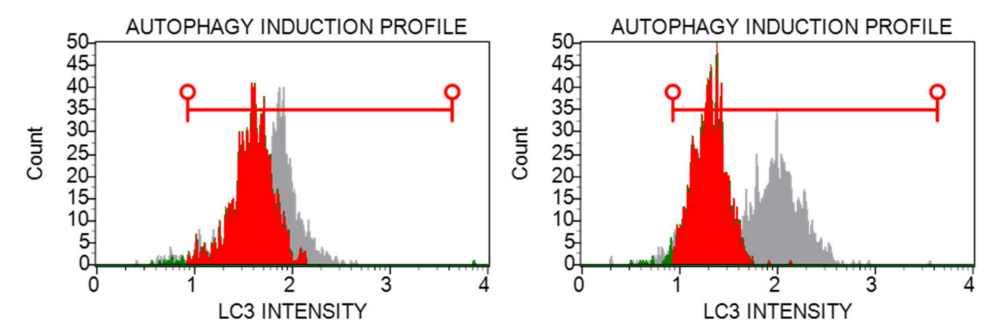

Figure 3. (a) Treatment with the multi enzyme inhibitor RK-682 inhibited cell proliferation in MGH-U3, T24 cells and UROtsa. Cells were incubated in serum-free media for $24 \mathrm{~h}$ and treated with different concentrations of RK-682 for a further $48 \mathrm{~h}$. The number of viable cells was measured by an MTS assay and expressed as a percentage of viable cells; (b) effect of RK-682 on MGH-U3 and T24 cells. RK-682 treatment resulted in a significant inhibition of MGH-U3 and T24 cell invasion $(p<0.05)$; (c) $48 \mathrm{~h}$ treatment with heparanase inhibitor RK-682 inhibited cell autophagy in MGH-U3 and T24 cells. The red horizontal line shows the range of LC3 intensity after KR-682 treatment. 


\subsection{In Vivo Growth of Urothelial Carcinoma Is Suppressed by RK-682 in the BBN-Induced Mouse Bladder Cancer Model}

The effects of the multi enzyme inhibitor RK-682 were tested using an in vivo model of bladder cancer treated with BBN (Figure 4a). Figure 4a briefly illustrates the experimental protocol for the present study. Six-week-old C57BL/6J mice were orally administered with $0.05 \%$ BBN. Bladder cancer-induced mice were prepared in approximately 22 weeks. The animals were divided into two groups, the treatment group $(n=7)$, and the non-treatment group $(n=5)$, totaling $n=14$ animals. The heparanase inhibitor RK-682 was administered at $2.5 \mathrm{mg} / 100 \mu \mathrm{L}$, into the bladder four times a week through a catheter inserted into the bladder.

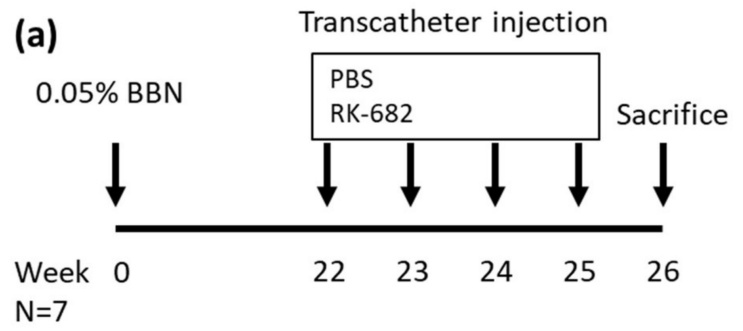

(b)

(c)

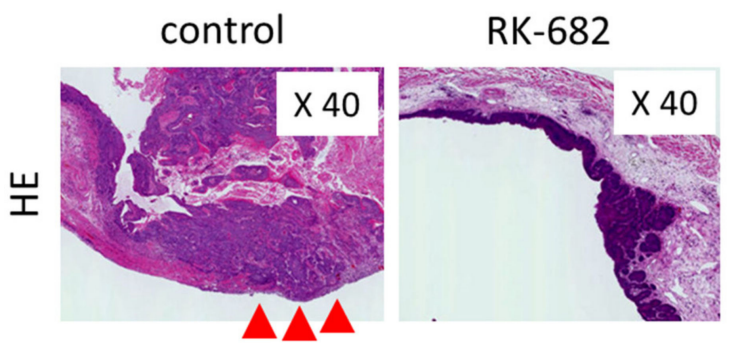

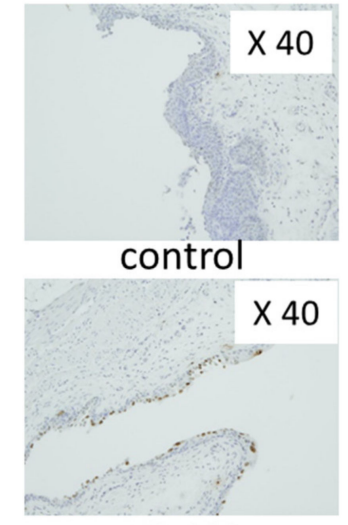

RK-682
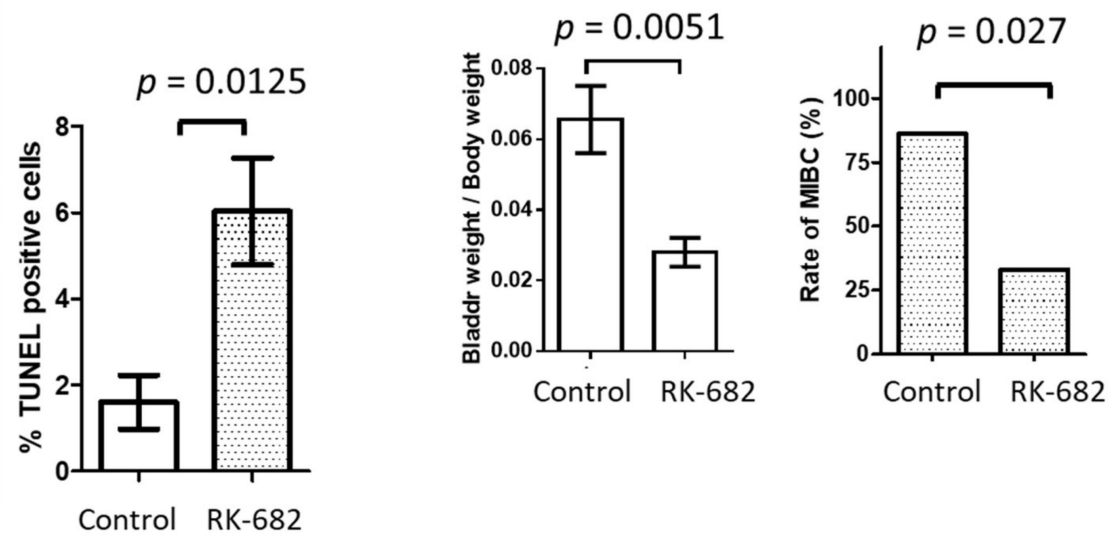

Figure 4. Intravesical injection of RK-682 inhibits in vivo tumor growth in the mouse N-butyl$\mathrm{N}$-(4-hydroxybutyl) nitrosamine (BBN)-induced bladder cancer implant model. (a) Diagrammatic experimental procedure; (b) RK-682 or control was transurethrally instilled into the bladder lumen. Bladders were resected post-instillation. Hematoxylin Eosin (HE) staining of bladder, comparison of bladder weight, ratio of muscle layer infiltration. Red triangle indicate images of muscle invasive bladder cancer.; (c) the percentage of cells in resected bladder specimens immunoreactive with TUNEL reagent, calculated per 1000 cells/in a high-power field. Each value is the mean \pm standard error.

There was no significant difference in body weight between the RK-682-treated group and the control group after the end of treatment. (RK-682 group vs. control group; $24.5 \mathrm{~g}$ vs. $25.6 \mathrm{~g} p=0.765$ ). There was a significant decrease in the bladder weight/body wight, (RK-682 group vs. control group; 0.028 vs. $0.056 p=0.0051$ ) and ratio of infiltrative bladder cancer (RK-682 group vs. control group; $28.6 \%$ vs. $85.7 \% p=0.027$ ) in the RK-682 treatment group compared to the control group (Figure $4 \mathrm{~b}$ ). A TUNEL assay showed that apoptosis was more frequent in the RK-682 treatment group (Figure 4c). IHC studies of the mouse tissue showed decreased expression of Ki67, LC3, and CD31 markers in the specimens from animals treated with RK-682. In contrast, E-cadherin expression level increased after treatment with the inhibitor (Figure 5). 


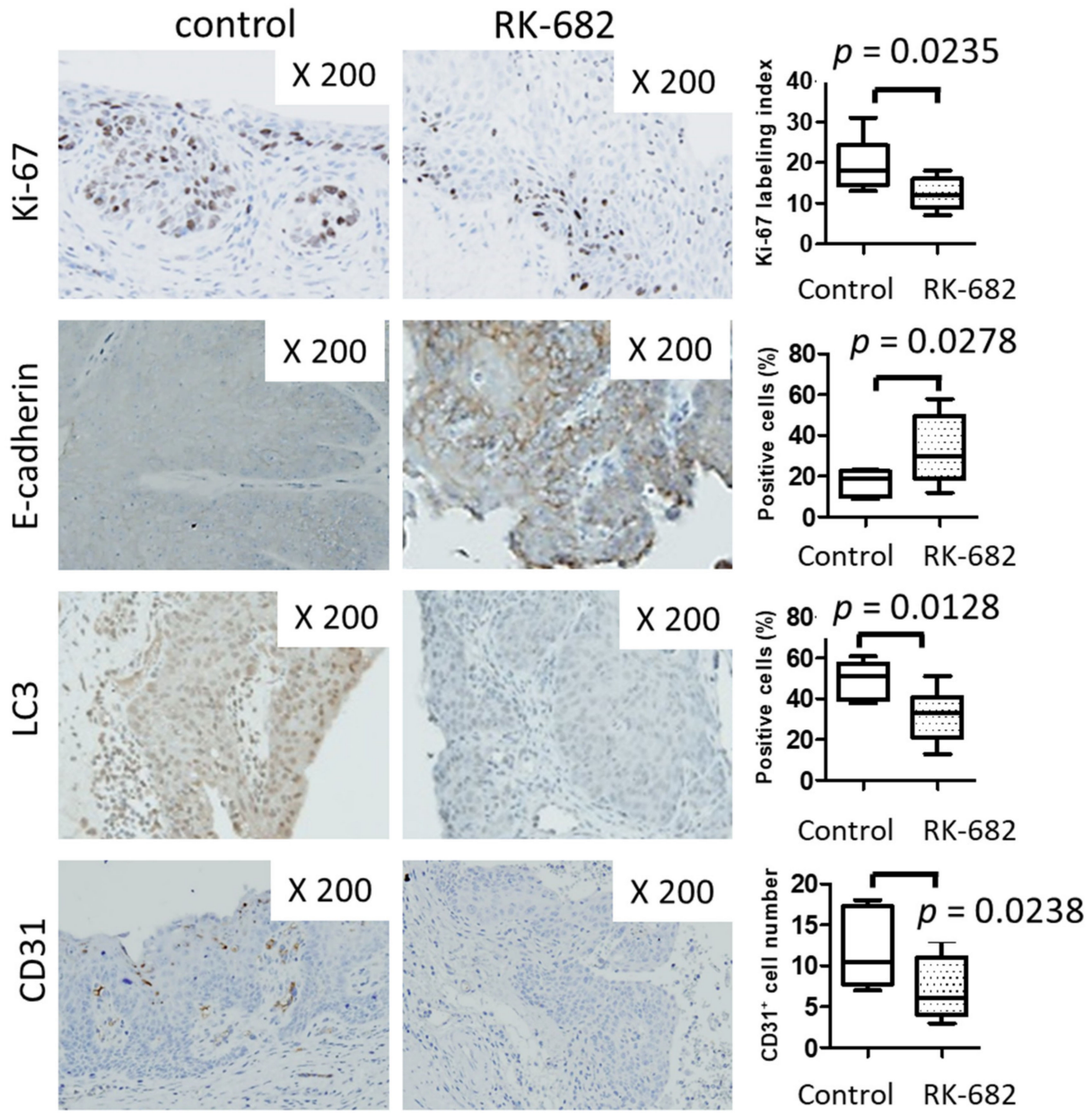

Figure 5. Immunohistochemical analysis of the mouse BBN-induced bladder cancer implant model. Immunohistochemistry for Ki-67, E-cadherin, LC3 and CD31 expression. The percentage of immunopositive cells was determined per 1000 cells in a high-power field.

\section{Discussion}

Heparanase expression is elevated in many types of tumors and is associated with more aggressive cancer and a poor prognosis $[3,13,14,26]$. We have previously reported that syndecan- 1 is involved in urothelial cancer development through the promotion of angiogenesis [10]. In this study, we investigated heparanase, an activator of syndecan-1, and analyzed its function in urothelial cancer. We have demonstrated that inhibition of heparanase suppresses cell proliferation, epithelial-mesenchymal transition (EMT), autophagy and angiogenesis.

In other cancer types, heparanase activation has been indicated in promoting metastasis and tumor progression. In bladder cancer, Gohji et al. [32] reported that cancer-specific survival rates are significantly lower when heparanase expression is elevated in bladder cancer patients. In our study, increased expression of heparanase in bladder cancer tissue samples correlated with higher recurrence rates within the bladder and progression to muscle-invasive cancer.

Chen et al. [30] suggested an association between heparanase expression and cell adhesion, and metastasis in hepatocellular carcinoma cell lines. Heparanase plays a proadhesive role in cell adhesion and tumor microembolus in hepatocellular carcinoma. In this study, inhibition of heparanase activity significantly reduced the ability of cancer cells to migrate and infiltrate. Furthermore, it was confirmed that the inhibition of autophagy resulted from heparanase inhibition.

Shteingauz et al. [33] reported the regulation of autophagy in normal and malignant cells by heparanse, conferring survival advantages and the development of resistance to chemotherapy. In the 
spontaneous bladder cancer mouse model, heparanase inhibition significantly suppressed bladder cancer invasion. This study confirmed that the suppression of heparanase induces apoptosis, suppresses cell proliferation and inhibits autophagy.

This report is the first to investigate heparanase inhibition and its effects on the suppression of cancer invasion, autophagy and apoptosis in bladder cancer. Intravesical treatment with a heparanase inhibitor did not result in serious side effects in the in vivo mouse model used here and hence this study was conducted as planned. As a treatment option for bladder cancer, intravesical infusion therapy allows the penetration of a drug directly into cancer cells and has mild side effects. In combination, these observations indicate that heparanase is a potential candidate for targeted therapy in bladder cancer.

This study has limitations. RK-682 is a multi-enzyme inhibitory locus targeting several enzymes including heparanase, protein tyrosine phosphatase (PTP), phospholipase A_2 and other enzymes. The T24 cell line is found to be less sensitive to siRNA inhibition compared with the MGH-U3 cell line, but is more sensitive to RK-682 inhibition. This may explain other effects of RK-682-mediated inhibition observed in this study. In UROtsa cells, the cell activity induced by siRNA was reduced by approximately $20 \%$. However, RK-682 treatment showed cytotoxicity in a dose-dependent manner. The cytotoxicity observed was 2-3 times higher compared to the cancer cell line. Expression analysis shows that RK-682 does have a heparanase inhibitory effect (Supplementary Figure S3). However, heparanase activity alone does explain changes in migration, invasion, and autophagy in bladder cancer cells. Further experiments are required to investigate the molecular function of heparanase.

\section{Materials and Methods}

\subsection{Cell Culture, Plasmids and Chemicals}

Human urothelial carcinoma cell lines MGH-U3, T24, and human urothelial cell line (UROtsa) were supplied by American Type Culture Collection (Manassas, VA, USA). MGH-U3 and T24 cells originated from human papillary bladder cancer [34]. T24 cells were cultured in RPMI1640 media supplemented with $10 \%$ fetal bovine serum and 50 units $/ \mathrm{mL}$ penicillin-streptomycin at $37^{\circ} \mathrm{C}$ in $5 \% \mathrm{CO}_{2}$.

The antibodies, anti-Ki67, LC3, and CD31, and E-cadherin, were purchased from Abcam (Cambridge, UK). The heparanase inhibitor RK-682 was purchased from Cayman Chemical Company (Ann Arbor, MI, USA). siRNA molecules were purchased from Thermo Fisher Scientific (K.K. Japan).

\section{2. siRNA Transfection of Heparanase}

For transfection analyses, $10^{6}$ cells from each cell line were seeded into 6-cm dishes. They were transfected with either $100 \mathrm{nM}$ of control RNA (Santa Cruz Biotechnology, Dallas, TX, USA) or with the heparanase siRNA. Transfections were performed with the Lipofectamine system (Invitrogen Japan, Tokyo, Japan) following the manufacturer's protocol.

The primers used were: HPSE sense 5'-AGUACUUGCGGUUACCCUATT-3'; HPSE antisense 5'-UAGGGUAACCGCAAGUACUTG-3' .

Actin sense 5'-CTCTTCCAGCCTTCCTTCCT-3'; Actin antisense 5'-AGCACTGTGTTGGCGTACAG-3' .

Gene expression analysis of cell cycle-related genes was performed by qPCR using the PrimerArray Cell Cycle (Takara, Otsu, Japan).

\subsection{Tissue Samples and Immunohistochemistry (IHC)}

This study was approved by the Medical Ethics Committee of Nara Medical University. The requirement for informed patient consent was waived due to the retrospective nature of the study (Study ID: NMU 900, July 23, 2013). A total of 57 patients diagnosed with organ-confined urothelial cancer between April 2007 and June 2010 at the Nara Medical University hospital were included in this study. The clinicopathological data and follow-up data were collected via a retrospective chart review. All pathological examinations were performed under the guidance of two pathologists (K.S. and N.K.) according to the 2009 TNM classification system [32]. All patients had bladder cancer 
and underwent transurethral resection of the bladder tumor (TURBT). IHC staining of 57 TURBT specimens using paraffin-embedded, formalin-fixed tissue blocks was performed as previously described [10,33]. Antibodies against heparinase were used as the primary antibodies at a dilution of 1:500. Staining was scored based on the positive cell ratio using standard light microscopy. Staining outcomes were evaluated by two independent observers (Y.T. and K.S), who were blinded to patient clinicopathological data.

\subsection{Cell Proliferation Assay}

The CellTiter 96 AQueous One Solution Cell Proliferation Assay (Promega, Madison, WI, USA) was used to measure cell proliferation by MTS assay as previously described [11]. Data were collected from triplicate experiments.

\subsection{Apoptosis Detection Assay}

Following the transfection with siRNA, cells were stained with propidium iodide (PI) and Fluorescein-5-isothiocyanate (FITC)-conjugated Annexin V (AV) following the manufacturer's protocol (TACS Annexin V-FITC kit; R\&D Systems). Apoptotic cells were quantified by calculating the number of cells positive for $\mathrm{AV}$ and negative for PI. Experiments were performed a minimum three times of duplicate.

\subsection{TdT-Mediated dUTP Nick End Labeling (TUNEL) Assay}

Formalin-fixed and paraffin-embedded 5-1-m thick sections of tumor specimens were stained using a TUNEL assay: Tumor TACS in situ apoptosis detection kit (R\&D Systems, Minneapolis, MN, USA). The apoptotic index (the number of apoptotic cells per total number of cells) was calculated as per 400 microscopic fields per sample.

\subsection{Cell Viability Assay}

UROtsa, MGH-U3 and T24 cells were seeded into 96-well plates at $2 \times 10^{3}$ cells/well and incubated overnight. The growth medium was removed, and the cells were washed once with phosphate-buffered saline (PBS). Fresh serum-free medium with or without heparinase inhibitor (RK-682) was applied. Cells were then treated with RK-682 (between 1-1000 nM) for $72 \mathrm{~h}$ to evaluate cell viability. The IC50 was determined based on the concentration-effect relationship using PRISM software version 5.00 (GraphPad Software, San Diego, CA, USA). Cell viability was measured using a Cell Counting Kit-8 (Dojindo, Kumamoto, Japan) according to the manufacturer's protocol. Absorbance was measured at $490 \mathrm{~nm}$ with a reference at $630 \mathrm{~nm}$ using an Infinite 200M PRO microplate autoreader (Tecan, Männedorf, Switzerland).

\subsection{Migration Assay}

A migration assay was performed using the BD Falcon FluoroBlok Insert System (Becton Dickinson, Franklin Lakes, NJ, USA) according to the manufacturer's instructions. Cells were starved in serum-free media for $24 \mathrm{~h}$, then seeded at a density of $2.5 \times 10^{4}$ cells/well in serum-free media plus RK-682 inhibitor. RPMI1640 media with 10\% FBS chemoattractant was contained within the lower wells. The cells were incubated in a humidified environment at $37^{\circ} \mathrm{C}$ with $5 \% \mathrm{CO}_{2}$ for $48 \mathrm{~h}$. Cells that were attached to the membrane were stained with the cell viability indicator Calcein AM Fluorescent Dye for $30 \mathrm{~min}$ (Promo Kine, Heidelberg, Germany) and quantified with an Infinite 200M PRO microplate spectrophotometer (Tecan, Männedorf, Switzerland) at $495 \mathrm{~mm}$ excitation and $515 \mathrm{~nm}$ emission. Cells were inspected via fluorescent microscopy.

\subsection{Autophagy Assay}

Autophagy assays were performed using Muse ${ }^{\mathrm{TM}}$ Cell Analyzer from Millipore (Hayward, CA, USA) following the manufacturer's instructions. Following treatment of MGH-U3 and T24 cells with 
heparinase inhibiter RK-682 (Cayman Chemical Company, Ann Arbor, MI, USA), the treated cells were washed with PBS buffer. The autophagy assays were analyzed using the Muse ${ }^{\mathrm{TM}}$ Autophagy LC3-antibody based kit (Millipore) according to the manufacturer's protocol.

\subsection{BBN-Induced Mouse Bladder Cancer Model}

An in vivo mouse model of bladder cancer was treated with BBN. Fourteen 6-week-old C57BL/6J female mice were obtained from Oriental Bio Service (Kyoto, Japan). All animal studies were approved by Nara Medical University affiliated Frist People's Hospital Committee on Use and Care of Animals and conducted in accordance with local humane animal care standard (Reference Number: 11389). BBN B0938 (Tokyo Chemical Industry, Tokyo, Japan) treated bladder cancer model mice were treated with the heparanase inhibitor RK-682 in the bladder once a week for four weeks by injection. Mice were randomized into a control group (control PBS, $n=7$ ) or heparanase inhibitor (RK-682, $n=7$ ) treatment group and received a single intravesical treatment instillation that was retained for $1 \mathrm{~h}$ with a purse-string suture. Mice were sacrificed (at week 25) after four treatments. Bladders were removed, placed open on filter paper, and fixed in 10\% neutral buffered formalin. Bladders were then embedded in paraffin, step-sectioned, and stained with hematoxylin-eosin (H\&E) and IHC staining for E-cadherin, Ki67, CD31 and LC3 (Abcam, Tokyo, Japan).

\subsection{Statistical Analysis}

Differences in cell migration were evaluated with the Student's $t$-test. The correlation of IHC staining intensity was assessed with the Man-Whitney U test. IBM SPSS Version 21 (SPSS Inc., Chicago, IL, USA) and PRISM software version 5.00 (San Diego, CA, USA) were used for statistical analyses and data plotting, respectively. Statistical significance was set at $p<0.05$, and all reported $p$ values were two-sided.

\section{Conclusions}

Heparanase induces invasion and autophagy in urothelial carcinoma. Downregulation of heparanase induces apoptosis. Heparanase may contribute to urothelial carcinoma cell survival and invasion.

Supplementary Materials: The following are available online at http://www.mdpi.com/1422-0067/21/11/3789/s1, Figure S1: Heparanse protein expression levels and mRNA expression levels in MGH-U3, T24 and U Rotsa cell lines, Figure S2: The suppression of heparanase protein expression and mRNA expression by knockdown with Si RNA MGH-U3, T24 and U Rotsa cell lines, Figure S3: The suppression of heparanase protein expression and mRNA expression by treated with the multi enzyme inhibitor RK-682 in MGH-U3, T24 and U Rotsa cell lines.

Author Contributions: Conceptualization, Y.T. and K.F.; Methodology, Y.T.; Software, Y.T. and T.F.; Validation, Y.T., K.S. and N.K.; Formal analysis, Y.T.; Investigation, Y.T., S.H., Y.M., Y.N., N.K. and K.F.; Resources, Y.T.; Data curation, Y.T., S.H. and Y.M.; Writing-Original draft preparation, Y.T.; Writing-Review and editing, M.M.; Visualization, Y.T.; Supervision, K.S., M.M., S.A., N.T., N.K. and K.F.; Project administration, Y.T., K.S. and M.M.; Funding acquisition, Y.T., N.K. and K.F. All authors have read and agreed to the published version of the manuscript.

Funding: This research received no external funding.

Acknowledgments: Editorial support, in the form of medical writing, assembling tables and creating high-resolution images based on authors' detailed directions, collating author comments, copyediting, fact-checking, and referencing, was provided by Editage, Cactus Communications.

Conflicts of Interest: The authors declare no conflict of interest.

\section{Abbreviations}

$\begin{array}{ll}\text { AV } & \text { Annexin V } \\ \text { FITC } & \text { Fluorescein-5-isothiocyanate } \\ \text { IC50 } & \text { half-maximal inhibitory concentration } \\ \text { IHC } & \text { Immunohistochemistry } \\ \text { PBS } & \text { phosphate-buffered saline }\end{array}$


PI propidium iodide

siRNA Small Interfering Ribonucleic Acid

qPCR Quantitative Polymerase Chain Reaction

TUNEL TdT-mediated dUTP nick end labeling

TURBT Transurethral resection of the bladder tumor

\section{References}

1. Sarrazin, S.; Lamanna, W.C.; Esko, J.D. Heparan sulfate proteoglycans. Cold Spring Harb. Perspect. Biol. 2011, 3, a004952. [CrossRef] [PubMed]

2. Hammond, E.; Khurana, A.; Shridhar, V.; Dredge, K. The Role of heparanase and sulfatases in the modification of heparan sulfate proteoglycans within the tumor microenvironment and opportunities for novel cancer therapeutics. Front. Oncol. 2014, 4, 195. [CrossRef] [PubMed]

3. Barash, U.; Cohen-Kaplan, V.; Dowek, I.; Sanderson, R.D.; Ilan, N.; Vlodavsky, I. Proteoglycans in health and disease: New concepts for heparanase function in tumor progression and metastasis. FEBS J. 2010, 277, 3890-3903. [CrossRef]

4. Dhodapkar, M.V.; Abe, E.; Theus, A.; Lacy, M.; Langford, J.K.; Barlogie, B.; Sanderson, R.D. Syndecan-1 is a multifunctional regulator of myeloma pathobiology: Control of tumor cell survival, growth, and bone cell differentiation. Blood 1998, 91, 2679-2688. [CrossRef]

5. Mahtouk, K.; Cremer, F.W.; Rème, T.; Jourdan, M.; Baudard, M.; Moreaux, J.; Requirand, G.; Fiol, G.; De Vos, J.; Moos, M.; et al. Heparan sulphate proteoglycans are essential for the myeloma cell growth activity of EGF-family ligands in multiple myeloma. Oncogene 2006, 25, 7180-7191. [CrossRef]

6. Derksen, P.W.; Keehnen, R.M.; Evers, L.M.; Van Oers, M.H.; Spaargaren, M.; Pals, S.T. Cell surface proteoglycan syndecan-1 mediates hepatocyte growth factor binding and promotes Met signaling in multiple myeloma. Blood 2002, 99, 1405-1410. [CrossRef]

7. Yang, Y.; MacLeod, V.; Dai, Y.; Khotskaya-Sample, Y.; Shriver, Z.; Venkataraman, G.; Sasisekharan, R.; Naggi, A.; Torri, G.; Casu, B.; et al. The syndecan-1 heparan sulfate proteoglycan is a viable target for myeloma therapy. Blood 2007, 110, 2041-2048. [CrossRef] [PubMed]

8. Nikolova, V.; Koo, C.Y.; Ibrahim, S.A.; Wang, Z.; Spillmann, D.; Dreier, R.; Kelsch, R.; Fischgrabe, J.; Smollich, M.; Rossi, L.H.; et al. Differential roles for membrane-bound and soluble syndecan-1 (CD138) in breast cancer progression. Carcinogenesis 2009, 30, 397-407. [CrossRef] [PubMed]

9. Shimada, K.; Nakamura, M.; Anai, S.; De Velasco, M.; Tanaka, M.; Tsujikawa, K.; Ouji, Y.; Konishi, N. A novel human AlkB homologue, ALKBH8, contributes to human bladder cancer progression. Cancer Res. 2009, 69, 3157-3164. [CrossRef]

10. Shimada, K.; Matsuyoshi, S.; Nakamura, M.; Ishida, E.; Konishi, N. Phosphorylation status of Fas-associated death domain-containing protein (FADD) is associated with prostate cancer progression. J. Pathol. 2005, 206, 423-432. [CrossRef] [PubMed]

11. Shimada, K.; Nakamura, M.; De Velasco, M.A.; Tanaka, M.; Ouji, Y.; Konishi, N. Syndecan-1, a new target molecule involved in progression of androgen-independent prostate cancer. Cancer Sci. 2009, 100, 1248-1254. [CrossRef] [PubMed]

12. Vlodavsky, I.; Ilan, N.; Naggi, A.; Casu, B. Heparanase: Structure, biological functions, and inhibition by heparin-derived mimetics of heparan sulfate. Curr. Pharm. Des. 2007, 13, 2057-2073. [CrossRef] [PubMed]

13. Vlodavsky, I.; Elkin, M.; Abboud-Jarrous, G.; Levi-Adam, F.; Fuks, L.; Shafat, I.; Ilan, N. Heparanase: One molecule with multiple functions in cancer progression. Connect. Tissue Res. 2008, 49, 207-210. [CrossRef]

14. Ilan, N.; Elkin, M.; Vlodavsky, I. Regulation, function and clinical significance of heparanase in cancer metastasis and angiogenesis. Int. J. Biochem. Cell Biol. 2006, 38, 2018-2039. [CrossRef]

15. Whitelock, J.M.; Iozzo, R.V. Heparan sulfate: A complex polymer charged with biological activity. Chem. Rev. 2005, 105, 2745-2764. [CrossRef]

16. Maeda, T.; Desouky, J.; Friedl, A. Syndecan-1 expression by stromal fibroblasts promotes breast carcinoma growth in vivo and stimulates tumor angiogenesis. Oncogene 2006, 25, 1408-1412. [CrossRef]

17. Weissmann, M.; Arvatz, G.; Horowitz, N.; Feld, S.; Naroditsky, I.; Zhang, Y.; Ng, M.; Hammond, E.; Nevo, E.; Vlodavsky, I.; et al. Heparanase-neutralizing antibodies attenuate lymphoma tumor growth and metastasis. Proc. Natl. Acad. Sci. USA 2016, 113, 704-709. [CrossRef] [PubMed] 
18. Zhang, Y.F.; Tang, X.D.; Gao, J.H.; Fang, D.C.; Yang, S.M. Heparanase: A universal immunotherapeutic target in human cancers. Drug Discov. Today 2011, 16, 412-417. [CrossRef] [PubMed]

19. Chen, T.; Tang, X.D.; Wan, Y.; Chen, L.; Yu, S.T.; Xiong, Z.; Fang, D.C.; Liang, G.P.; Yang, S.M. HLA-A2-restricted cytotoxic $\mathrm{T}$ lymphocyte epitopes from human heparanase as novel targets for broad-spectrum tumor immunotherapy. Neoplasia (N. Y. NY) 2008, 10, 977-986. [CrossRef] [PubMed]

20. Baburajeev, C.P.; Mohan, C.D.; Rangappa, S.; Mason, D.J.; Fuchs, J.E.; Bender, A.; Barash, U.; Vlodavsky, I.; Basappa; Rangappa, K.S. Identification of novel class of triazolo-thiadiazoles as potent inhibitors of human heparanase and their anticancer activity. BMC Cancer 2017, 17, 235. [CrossRef]

21. Miao, H.Q.; Liu, H.; Navarro, E.; Kussie, P.; Zhu, Z. Development of heparanase inhibitors for anti-cancer therapy. Curr. Med. Chem. 2006, 13, 2101-2111. [CrossRef] [PubMed]

22. Parish, C.R.; Freeman, C.; Brown, K.J.; Francis, D.J.; Cowden, W.B. Identification of sulfated oligosaccharide-based inhibitors of tumor growth and metastasis using novel in vitro assays for angiogenesis and heparanase activity. Cancer Res. 1999, 59, 3433-3441. [PubMed]

23. Borsig, L. Antimetastatic activities of modified heparins: Selectin inhibition by heparin attenuates metastasis. Semin. Thromb. Hemost. 2007, 33, 540-546. [CrossRef] [PubMed]

24. Vlodavsky, I.; Friedmann, Y.; Elkin, M.; Aingorn, H.; Atzmon, R.; Ishai-Michaeli, R.; Bitan, M.; Pappo, O.; Peretz, T.; Michal, I.; et al. Mammalian heparanase: Gene cloning, expression and function in tumor progression and metastasis. Nat. Med. 1999, 5, 793-802. [CrossRef]

25. Hulett, M.D.; Freeman, C.; Hamdorf, B.J.; Baker, R.T.; Harris, M.J.; Parish, C.R. Cloning of mammalian heparanase, an important enzyme in tumor invasion and metastasis. Nat. Med. 1999, 5, 803-809. [CrossRef]

26. Parish, C.R.; Freeman, C.; Hulett, M.D. Heparanase: A key enzyme involved in cell invasion. Biochim. Biophys. Acta 2001, 1471, M99-M108. [CrossRef]

27. Vlodavsky, I.; Friedmann, Y. Molecular properties and involvement of heparanase in cancer metastasis and angiogenesis. J. Clin. Investig. 2001, 108, 341-347. [CrossRef]

28. Vlodavsky, I.; Beckhove, P.; Lerner, I.; Pisano, C.; Meirovitz, A.; Ilan, N.; Elkin, M. Significance of heparanase in cancer and inflammation. Cancer Microenviron. 2012, 5, 115-132. [CrossRef]

29. Jung, O.; Trapp-Stamborski, V.; Purushothaman, A.; Jin, H.; Wang, H.; Sanderson, R.D.; Rapraeger, A.C. Heparanase-induced shedding of syndecan-1/CD138 in myeloma and endothelial cells activates VEGFR2 and an invasive phenotype: Prevention by novel synstatins. Oncogenesis 2016, 5, e202. [CrossRef]

30. Chen, X.-P.; Luo, J.-S.; Tian, Y.; Nie, C.-L.; Cui, W.; Zhang, W.-D. Downregulation of heparanase expression results in suppression of invasion, migration, and adhesion abilities of hepatocellular carcinoma cells. BioMed Res. Int. 2015, 2015, 241983. [CrossRef]

31. Comperat, E.M.; Burger, M.; Gontero, P.; Mostafid, A.H.; Palou, J.; Roupret, M.; van Rhijn, B.W.G.; Shariat, S.F.; Sylvester, R.J.; Zigeuner, R.; et al. Grading of urothelial carcinoma and the new "world health organisation classification of tumours of the urinary system and male genital organs 2016". Eur. Urol. Focus 2019, 5, 457-466. [CrossRef] [PubMed]

32. Gohji, K.; Okamoto, M.; Kitazawa, S.; Toyoshima, M.; Dong, J.; Katsuoka, Y.; Nakajima, M. Heparanase protein and gene expression in bladder cancer. J. Urol. 2001, 166, 1286-1290. [CrossRef]

33. Shteingauz, A.; Boyango, I.; Naroditsky, I.; Hammond, E.; Gruber, M.; Doweck, I.; Ilan, N.; Vlodavsky, I. Heparanase enhances tumor growth and chemoresistance by promoting autophagy. Cancer Res. 2015, 75, 3946-3957. [CrossRef] [PubMed]

34. Sabichi, A.; Keyhani, A.; Tanaka, N.; Delacerda, J.; Lee, I.L.; Zou, C.; Zhou, J.H.; Benedict, W.F.; Grossman, H.B. Characterization of a panel of cell lines derived from urothelial neoplasms: Genetic alterations, growth in vivo and the relationship of adenoviral mediated gene transfer to coxsackie adenovirus receptor expression. J. Urol. 2006, 175, 1133-1137. [CrossRef]

(C) 2020 by the authors. Licensee MDPI, Basel, Switzerland. This article is an open access article distributed under the terms and conditions of the Creative Commons Attribution (CC BY) license (http://creativecommons.org/licenses/by/4.0/). 